\title{
Increasing acceptance of chlorination for household water treatment: observations from Bangladesh
}

\author{
SARA V. FLANAGAN, XIAOGUANG MENG and \\ YAN ZHENG
}

Point-of-use water treatment, especially chlorination, is an effective intervention to reduce diarrhoea, a leading cause of death for children under five. Yet success in chlorination uptake has been limited. One obstacle is objection to treated water's taste/odour. Protective chlorine residuals that are not offensive to users require accurate dosing - a challenge in practice. Further, taste sensitivity may be different for populations never exposed to chlorinated water. Here, household chlorination trials in Bangladesh similarly revealed dissatisfaction with treated water due to taste and odour, although attempts to quantify chlorine sensitivity disputed the dissatisfaction at lower residuals. A granular activated carbon (GAC) filter fitted to the spigot of a covered tank removed the remaining chlorine residual prior to drinking and increased user satisfaction. Such a filter removes taste as a barrier and allows over-dosing contaminated water to ensure disinfection, with implications for areas with high source water variability and for emergency situations.

Keywords: chlorination, household water treatment, water-borne infectious disease, point-of-use, Bangladesh, granular activated carbon, disinfection

DiARRHOEA IS STILL the second leading cause of death for children under five globally and pathogen contamination through food and drinking water remains a major pathway. The health benefits of water quality improvements are well established, though the benefit can still be reduced by other poor sanitation and hygiene practices. Transitions to treated water supply are often marked by clear drops in disease and mortality. Filtration and chlorination of public water supply in the United States is credited for nearly half of the total mortality reduction in major cities, three-quarters of the infant mortality reduction, and nearly two-thirds of the child mortality reduction when mortality rates fell most rapidly during the late 19th and early 20th centuries (Cutler and Miller, 2004). Water-quality improvements in developing countries today continue to show great reductions in water-borne disease burden (Fewtrell et al., 2005; Clasen et al., 2007b). Because water supply infrastructure is often inadequate in developing countries, several point-of-use treatment interventions have been shown to both improve the microbial quality

Sara Flanagan works with UNICEF Bangladesh; Xiaoguang Meng is with the

Stevens Institute of Technology, Hoboken, New Jersey, USA; and Yan Zheng (yan.zheng@qc.cuny.edu,yzheng@ldeo.columbia.edu) is with Queens College, City University of New York, and Lamont-Doherty Earth Observatory, Columbia University.

(c) Practical Action Publishing, 2013, www.practicalactionpublishing.org doi: 10.3362/1756-3488.2013.014, ISSN: 0262-8104 (print) 1756-3488 (online) 
of household water and reduce diarrhoeal disease in users (Fewtrell et al., 2005; Arnold and Colford, 2007; Clasen et al., 2007b), although the lack of blinded trials showing health effects has left some with questions about the role of household water treatment.

Among common point-of-use interventions, household chlorination has been shown to be the most cost effective where resources are limited, at an annual cost of US\$0.66 per person (Clasen et al., 2007a). Chlorine inactivates the vast majority of human pathogenic bacteria, although reduction of protozoa such as cryptosporidium requires a higher level of free chlorine (Sobsey, 1989). Additional advantages of chlorination are that it offers residual protection against recontamination during storage or handling and is also relatively easy to use (Lantagne, 2008). In developed countries where mandatory chlorination has been practised for decades, the populations have generally adjusted to low levels of chlorine residual in the drinking water to the extent where it is largely unnoticeable. Most water-distribution systems in developed nations maintain between 0.2 and $1.0 \mathrm{mg} / \mathrm{L}$ of free chlorine (WHO, 2004). Among those remaining dissatisfied with the taste of chlorinated water, the use of household filters to remove chlorine from tap water or even the consumption of exclusively bottled water has become common.

Promotion of chlorination as a point-of-use water intervention in many developing countries has had some success, although many barriers have also been identified (Lantagne et al., 2006). When the supplies are available and the technique of adding the appropriate chlorine dose to water is easy, it has been found favourable as a treatment method (Lantagne et al., 2006), although taste and smell are frequent complaints from household chlorination users and achieving high uptake continues to be a challenge. For example, an independent evaluation of a national programme in Zambia marketing a subsidized sodium hypochlorite product called Clorin since 1998 found that among households in areas receiving considerable social marketing and with substantial distribution of Clorin, only 13 per cent had residual chlorine in drinking water at an unannounced visit. The only statistically significant reasons reported for stopping Clorin use were affordability, taste imparted to water, and smell of Clorin (Olembo et al., 2004).

The WHO recommends that free chlorine residuals in treated water do not exceed $5 \mathrm{mg} / \mathrm{L}$, with an optimal range at point of delivery of $0.2 \mathrm{mg} / \mathrm{L}$ in normal circumstances to $0.5 \mathrm{mg} / \mathrm{L}$ in high-risk circumstances (WHO, 2004). A free chlorine residual range of $<2.0 \mathrm{mg} / \mathrm{L}$ after 1 hour and $>0.2 \mathrm{mg} / \mathrm{L}$ after 24 hours of dosing has been proposed for household treatment (Lantagne, 2008).

Free chlorine taste tests have shown there is high interpersonal variability in sensitivity to chlorine as well as geographical variability in average sensitivity of populations. For example, the sensitivity limit to free chlorine of average American populations was found to be $0.8 \mathrm{mg} / \mathrm{L}$ (Mackey et al., 2004). This may be linked to local chlorination residual practices, as another study found an untrained American panel was five to ten times less sensitive to chlorine flavour than an untrained French panel, about the same magnitude as the difference between the residual maintained in the US (1.0-3.0 mg/L) versus France (0.1-0.2 mg/L) (Piriou et al., 2004). 
Attempts to quantify the sensitivity to chlorine of traditionally unexposed populations in developing countries are, however, limited. In Ethiopia, focus group participants did not taste the chlorine residual at $1.0 \mathrm{mg} / \mathrm{L}$, noticed the residual at $2.0 \mathrm{mg} / \mathrm{L}$, found the taste objectionable at $3.0 \mathrm{mg} / \mathrm{L}$, and found the water unsuitable for drinking at $4.0 \mathrm{mg} / \mathrm{L}$. In Zambia, participants did not notice a taste at $0.2 \mathrm{mg} / \mathrm{L}$ but tasted the residual at $1.0 \mathrm{mg} / \mathrm{L}$ although they did not find it objectionable, found the $2.0 \mathrm{mg} / \mathrm{L}$ residual too strong and bitter, and refused to taste the water at $3.0 \mathrm{mg} / \mathrm{L}$ (Lantagne, 2008). These results indicate that there might be geographic variability in sensitivity among unexposed populations as well, in addition to the interpersonal variability noted from developed country studies.

Recognizing that taste is a barrier to chlorination, a small-scale trial was conducted in an urban slum of Dhaka, Bangladesh, to ascertain whether removing residual chlorine through a filter would improve user satisfaction with chlorinated water. As part of the trial, sensitivity to the taste of chlorine in local populations unexposed to chlorine was also evaluated.

\section{Methods}

\section{Taste trial}

Our trials were modelled after the forced-choice triangle taste test methods used by various water utility companies in developed countries (SCA, 2010). Volunteers are presented with a series of dilutions one at a time, each along with two reference blanks. If the volunteer can identify a test sample as having a taste/odour then the procedure is repeated with a diluted sample. The threshold level is reached when a sample has been identified twice at one dilution but the volunteer has failed to identify it at the next dilution. The pooled results of volunteers provide insight to average thresholds of taste and odour for a substance despite interpersonal variability.

Chlorine taste tests were held among volunteers of both sexes and various ages from an urban slum $(n=20)$ and a rural village $(n=10)$ in the summer and autumn of 2011. Here, each volunteer was presented with three small cups of water, one containing some concentration of free chlorine and the others without, and asked to determine which sample was different from the other two. If the volunteer was able to correctly identify the cup containing chlorine twice in a row then the test was repeated with a more diluted sample.

\section{Chlorination trial}

Beginning mid-September 2011, 11 households in an urban slum participated in a trial in which they were given a 14-L plastic tank with a spigot and a screw top enclosure for drinking water storage (Gazi, Bangladesh, retail price \$5). Each household was instructed to chlorinate at a pre-determined dose specific to their water source to obtain an acceptable residual level using a 15-ml plastic dropper bottle (Bismillah Plastics, Bangladesh) filled with diluted commercially available 
sodium hypochlorite solution (5.25 per cent, Clotech Bangladesh). Households were surveyed on socio-economic characteristics and water use behaviours prior to the trial. The eleven households are from two clusters each sharing stoves, a latrine, and a water point - a reservoir of $2.5 \mathrm{~m}^{3}$ filled by municipal water and accessed by a hand pump. Prior to this trial there was some awareness of the need to treat water by boiling, but most households did not do so regularly because of the time involved. Follow-up visits were made to test microbial quality and chlorine residual of drinking water, although absences due to outside employment occasionally prevented sample collection from all households. Free chlorine was measured using an eXact Chlorine Photometer (Industrial Testing Systems, USA) with DPD test strips. After one month of treating their drinking water with chlorine, households were surveyed on their satisfaction with chlorination and the treated water.

In October 2011, each household's tank was replaced with one that was identical except that it had a chlorine-removal filter added inside (Figure 1) and it had an easier to use spigot. This granular activated carbon (GAC) filter, designed and made by the authors, was connected to the spigot and removed the free chlorine residual as the chlorinated water was dispensed through it. Laboratory tests demonstrated that the filter is capable of producing $10 \mathrm{~L} /$ hour and removing free chlorine from as high as $5 \mathrm{mg} / \mathrm{L}$ to less than the detection limit (Figure 2). No chlorine breakthrough in the GAC filter is expected to occur because the low concentration hypochlorite is not stable and will degrade. The GAC filter was made of a 250-ml HDPE plastic bottle with holes drilled through (Nalgene, $\$ 1.50$ each in the US), $250 \mathrm{~mL}$ of GAC $(\$ 0.62$ at the US retail price of $\$ 2.50 / \mathrm{L}$ ), and bridal veil used as a filter screen (material cost less than $\$ 0.10$ ). The spigot was purchased in China at a cost of less than $\$ 1$. The total material cost of the GAC-spigot assembly was less than $\$ 5$.

Households continued chlorinating their drinking water using the GAC filter tank for another month, during which visits to test water quality and chlorine residual were made and after which another round of user surveys was conducted.

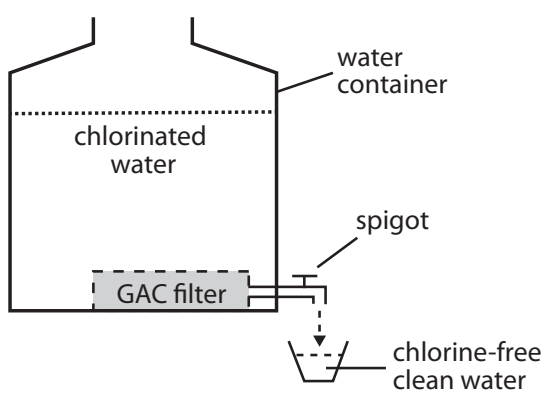

Figure $1 \mathrm{GAC}$ filter fitted to spigot of water tank

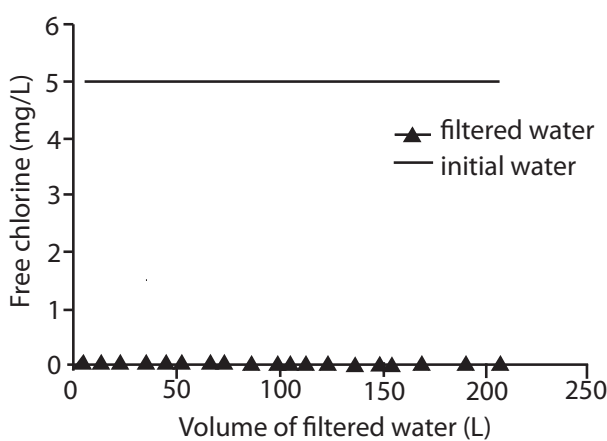

Figure 2 Removal of chlorine during filtration of water in laboratory tests conducted at Stevens Institute of Technology 


\section{Results}

\section{Taste trial}

Given that recommended chlorine residuals are usually low $(0.2-0.5 \mathrm{mg} / \mathrm{L})$ yet taste is a frequent complaint, we intended to start at a higher concentration of free chlorine so that it could be diluted further until a threshold was reached. The initial samples of each test contained a chlorine residual concentration between 1.0 and $1.7 \mathrm{mg} / \mathrm{L}$ but, unexpectedly, very few of the volunteers were able to identify the water containing chlorine; only three of 30 were able to identify the correct sample both times. That is roughly the number to be expected if volunteers had selected each sample completely randomly. Only one volunteer was able to correctly identify the higher concentration sample twice and then the diluted sample of $0.55 \mathrm{mg} / \mathrm{L}$ twice as well (Table 1).

Table 1 Taste test results, Bangladesh

\begin{tabular}{llll}
\hline Chlorine concentration & Performance & Trial result & Chance probability \\
\hline $1.0-1.7 \mathrm{mg} / \mathrm{L}$ & Identify once & 9 out of 30 & 10 out of $30(1 / 3)$ \\
& Identify twice & 3 out of 30 & 3 out of $30(1 / 9)$ \\
$0.55 \mathrm{mg} / \mathrm{L}$ & Identify twice & 1 out of 30 & $<1$ out of $30(1 / 81)$ \\
\hline
\end{tabular}

Note: 30 participants: 13 female, 17 male; ages $4-40$

\section{Chlorination trial}

Samples collected at two time points during each month indicated a presence of residual chlorine in the majority of stored water tanks (Table 2), showing high levels of actual use. Out of 14 free chlorine tests performed during household visits over the first month, only once was a residual found above $0.5 \mathrm{mg} / \mathrm{L}$; the rest were below the levels tried in the taste tests. Yet in user surveys all eleven households commented on the smell and taste of the water, eight households concluded they were unsatisfied with the treated water because of it, and two households even reported stopping adding the chlorine to their collected water (Table 3 ).

After another month of chlorinating their water using the new tank fitted with the GAC filter, the households were surveyed again and all eleven reported that they were satisfied with the water and continued to use the chlorine, some commenting that there was no smell in the water which allowed them to use more chlorine than before (Table 3). The free chlorine residuals inside the tank were generally observed to be the same as previously (because dosage recommendations remained the same), although one sample was found as high as $2.34 \mathrm{mg} / \mathrm{L}$, indicating that the filter succeeded in removing the objectionable aspects of the treated water and perhaps even increased enthusiasm for adding chlorine. Laboratory tests confirmed that chlorine-free water samples dispensed from GAC filter-fitted tanks were free from Escherichia coli despite contaminated source waters measuring up to 4,000 CFU/100 $\mathrm{ml}$ (Table 2) when the water inside the tank contained measureable chlorine 
residual $(n=12)$. We do not know why three stored household water samples in tanks without filters, all collected on the first day of follow up, contained low levels of $E$. coli despite having residual chlorine.

Table 2 Presence of chlorine and E. coli in household stored water

\begin{tabular}{llcccc}
\hline $\begin{array}{l}\text { Water } \\
\text { sample }\end{array}$ & $\begin{array}{c}\text { No. of } \\
\text { samples } \\
\text { collected }\end{array}$ & $\begin{array}{c}\text { Presence of } \\
\text { chlorine in } \\
\text { tank water (\%) }\end{array}$ & $\begin{array}{c}\text { E. coli } \\
\text { contamination } \\
\text { in samples (\%) }\end{array}$ & $\begin{array}{c}\text { Range } \\
(\text { CFU/100 ml) } \\
\text { E. coli }\end{array}$ \\
\hline $\begin{array}{l}\text { Phase 1 } \\
\text { (no filter) }\end{array}$ & Stored HH water & 14 & 78.6 & $21.4^{1}$ & $0-63$ \\
Phase 2 & Source water & 2 & - & 100 & $19-4,000$ \\
(filter) & Stored HH water & 17 & 70.6 & $5.9^{2}$ & $0-92$ \\
\hline
\end{tabular}

$1(n=3)$ collected on first day of sampling, chlorine residual measured

$2(n=1)$ no chlorine residual measured

Table 3 Reported use and satisfaction with chlorination

\begin{tabular}{|c|c|c|c|}
\hline Household & Add chlorine? & Satisfied with treated water? & Comment \\
\hline \multicolumn{4}{|c|}{ Survey after Phase 1} \\
\hline 1 & Yes & No & Smell \\
\hline 2 & Stopped & No & Taste and smell \\
\hline 3 & Yes & No & Smell \\
\hline 4 & Stopped & No & Smell \\
\hline 5 & Yes & No & Smell \\
\hline 6 & Yes & No & Smell \\
\hline 7 & Yes & No & Smell \\
\hline 8 & Yes & No & Smell \\
\hline 9 & Yes & Yes & Better if no smell \\
\hline 10 & Yes & Yes & Smelly taste \\
\hline 11 & Yes & Yes & Better if no smell \\
\hline \multicolumn{4}{|c|}{ Survey after Phase 2} \\
\hline 1 & Yes & Yes & No smell \\
\hline 2 & Yes & Yes & $\begin{array}{l}\text { Can use more chlorine but } \\
\text { no smell/taste }\end{array}$ \\
\hline 3 & Yes & Yes & Can use more chlorine now \\
\hline 4 & Yes & Yes & \\
\hline 5 & Yes & Yes & \\
\hline 6 & Yes & Yes & \\
\hline 7 & Yes & Yes & \\
\hline 8 & Yes & Yes & \\
\hline 9 & Yes & Yes & \\
\hline 10 & Yes & Yes & \\
\hline 11 & Yes & Yes & \\
\hline
\end{tabular}




\section{Discussion}

Dislike of the taste or smell of chlorinated water are common complaints for the treatment method (Luoto et al., 2012). Although in limited cases some users have expressed a preference for the chlorine taste as a quality assurance of safe water, to populations unexposed to drinking chlorinated water dissatisfaction with taste and smell remains as a barrier to acceptance and widespread uptake. A recent survey of implementers of point-of-use water treatment projects cited aesthetics (taste, colour, odour) of water as the concern most often expressed by product users (Lantagne and Clasen, 2012).

Research suggests that high adherence is essential in order to realize potential health gains from household water treatment (Brown and Clasen, 2012). As satisfaction with the treated water is critical for adherence to treatment methods, addressing these commonly perceived problems is valuable. The ideal chlorine dose would effectively treat the microbial contamination of the source water and maintain a protective residual. But at the same time this free chlorine residual should not result in water with a smell or taste that is too offensive to the user. In this sense accurately dosing to the needs of the particular water source is essential.

Finding an optimal dose for water can be difficult, considering the variability in local sources and conditions, and it would not be realistic for every water source to go through the testing required to determine its optimal dose. Lantagne (2008) evaluated 106 drinking water sources for effective chlorine dose, including surface water, open shallow wells, and intermittently flowing piped systems in 13 less developed countries and determined for water with turbidity of $<10 \mathrm{ntu}$, a sodium hypochlorite dose of $1.875 \mathrm{mg} / \mathrm{L}$ was sufficient to meet the WHO proposed range for treated water. Surface water will frequently have high organic matter which will generate chlorine demand, but the inorganic chlorine demand of groundwater can also be highly variable depending on the water chemistry of the location. For example, the commonly used groundwater in Bangladesh can be high in iron, manganese, or arsenic. A chlorine dose must be large enough to meet these chemical demands beyond the amount required to inactivate pathogens and still have a protective residual remaining.

In addition to limits on optimizing a dose due to high variability of source water and chlorine demand, variability in actual chlorine concentration of commercially available products is another challenge to accurate dosing at the household level. In the midst of these practical challenges, the potential barriers of unknown chlorine sensitivity thresholds put an even greater burden on the accuracy of dosing.

These initial taste trials seem to suggest that chlorine taste should not be an issue in Bangladesh as long as residual chlorine levels are at least below $1 \mathrm{mg} / \mathrm{L}$. As this is above the recommended residual range, water that is dosed correctly should not elicit the same taste complaints. But, our own household trials conducted in these communities as well as other ongoing studies in Bangladesh have observed complaints about taste and odour in chlorinated water. Clearly there are some aspects of the experience of drinking treated water in practice that were not captured in the 
taste tests we conducted. There was no separate odour component of our test, and given that the majority of complaints from households were about smell then it is possible the cups given to test participants were not full enough for the chlorinated water to elicit the same odour response that drinking the household water did, or some other aspect of the sample water did not result in the same noticeable odour. Given that chlorine treated water still seems to create user dissatisfaction, there is scope for further investigation. For example, GAC can also remove natural organic matter and disinfection by-products, including trihalomethanes (THMs), which cause smell and taste in water (Capar and Yetis, 2002).

\section{Lessons learned}

There are several messages to take away from these findings in Bangladesh. First, although the trial was small-scale and the number of households does not give enough power to analyse the results further or reach any conclusions, these observations suggest that removing the taste and smell effect of the chlorine residual while keeping everything else the same can directly increase satisfaction with treated water. Second, removing the residual prior to drinking allows maintenance of a higher protective residual inside the storage tank. Correct dosage is key to ensuring safe disinfection of water without alienation of users, but such a filter permits over-dosing unknown water sources with hypochlorite solution to guarantee safe water that will not offend the drinkers.

This is an important option both for scaling-up chlorination as a treatment method in areas with variable water sources, as well as in emergency situations when questionable water sources can be over-chlorinated to ensure higher quality drinking water. A study of point-of-use water treatment in emergency settings by Lantagne and Clasen (2012) concluded that 'the lack of user acceptability of high chlorine dosages significantly affects chlorination projects in emergencies, and appropriate dosage regimes should be developed' and recommended that chlorine dosage be considered in light of user acceptability concerns. Employing dechlorination filters could increase user acceptability and avoid some of these significant dosing challenges in emergency settings.

Reproducing this filter with locally available materials will make it more affordable and cost-effective in developing countries. Adapting the filter to allow a small amount of water still containing the chlorine residual to be dispensed along with the de-chlorinated water could also account for any chance of contamination from the cup used to drink the water. Finally, water treatment in general is more successful when accompanied by a safe water storage system that protects against continued contamination in addition to the protective residual of the water inside. For this reason the filters in Bangladesh were only used connected to the spigot on the interior of the closed tank. 


\section{Conclusion}

Innovative research to improve acceptance of water treatment methods will be critical in ensuring greater uptake of methods in developing countries where large-scale water supply infrastructure development is still in process. By removing the barrier of taste, as done in these household trials by employing a granular activated carbon filter, it may be possible to increase satisfaction with and therefore use of chlorination as a point-of-use treatment. In this small trial the method was clearly demonstrated and the tools readily available; households were provided with dropper bottles for chlorine and the plastic storage tank with spigot that was popular among users. The only expressed reason for dissatisfaction was the taste and smell of the treated water, which was no longer a problem once the filter was in use. Although the size of this pilot limits recommendations of these methods at scale, these initial observations highlight the potential value in addressing issues of acceptance for household water treatment through further research.

\section{References}

Arnold, B.F. and Colford, J.M. Jr (2007) 'Treating water with chlorine at point-of-use to improve water quality and reduce child diarrhea in developing countries: a systematic review and meta-analysis', American Journal of Tropical Medicine and Hygiene 76: 354-64.

Brown, J. and Clasen, T. (2012) 'High adherence is necessary to realize health gains from water quality interventions', PLoS One 7: e36735. <http://dx.doi.org/10.1371/journal.pone.0036735>

Capar, G. and Yetis, Ü. (2002) 'Removal of THM precursors by GAC: Ankara case study', Water Research 36: 1379-84. <http://dx.doi.org/10.1016/S0043-1354(01)00334-7>

Clasen, T., Haller, L., Walker, D., Bartram, J. and Cairncross, S. (2007a) 'Cost-effectiveness of water quality interventions for preventing diarrhoeal disease in developing countries', Journal of Water and Health 5(4): 559-608. <http://dx.doi.org/10.2166/wh.2007.010>

Clasen, T., Schmidt, W.P., Rabie, T., Roberts, I. and Cairncross, S. (2007b) 'Interventions to improve water quality for preventing diarrhoea: systematic review and meta-analysis', British Medical Journal 334 (7597): 782-85. <http://dx.doi.org/10.1136/bmj.39118.489931.BE>

Cutler, D. and Miller, G. (2004) The Role of Public Health Improvements in Health Advances: The 20th Century United States, National Bureau of Economic Research Working Paper No. 10511, Cambridge, MA: NBER.

Fewtrell, L., Kaufmann, R., Kay, D., Enanoria, W., Haller, L. and Colford, J. (2005) 'Water, sanitation, and hygiene interventions to reduce diarrhoea in less developed countries: a systematic review and meta-analysis', Lancet Infectious Diseases 5: 42-52. <http://dx.doi. org/10.1016/S1473-3099(04)01253-8>

Lantagne, D.S. (2008) 'Sodium hypochlorite dosage for household and emergency water treatment', American Water Works Association Journal 100: 106-19.

Lantagne, D. and Clasen, T. (2012) 'Point-of-use water treatment in emergency response', Waterlines 31: 30-52. <http://dx.doi.org/10.3362/1756-3488.2012.005>

Lantagne, D., Quick, R. and Mintz, E. (2006) Household Water Treatment and Safe Storage in Developing Countries: A Review of Current Implementation Practices, Washington, DC: Woodrow Wilson International Center for Scholars' Environmental Change and Security Program. 
Luoto, J., Mahmud, M., Albert, J., Luby, S., Najnin, N., Unicomb, L. and Levine, D.I. (2012) 'Learning to dislike safe water products: Results from a randomized controlled trial of the effects of direct and peer experience on willingness to pay', Environmental Science \& Technology 46: 6244-51. <http://dx.doi.org/10.1021/es2027967>

Mackey, E.D., Baribeau, H., Crozes, G.F., Suffet, I.H. and Piriou, P. (2004) 'Public thresholds for chlorinous flavors in U.S. tap water', Water Science and Technology 49: 335-40.

Olembo, L., Kaona, F., Tuba, M. and Burnham, G. (2004) Safe Water Systems: An Evaluation of the Zambia CLORIN Program (Final Report), Washington, DC: US Agency for International Development.

Piriou, P., Mackey, E.D., Suffet, I.H. and Bruchet, A. (2004) 'Chlorinous flavor perception in drinking water', Water Science \& Technology 49: 321-28.

Sobsey, M.D. (1989) 'Inactivation of health-related microorganisms in water by disinfection processes', Water Science \& Technology 21: 179-95.

Standing Committee of Analysts (SCA) (2010) Blue Book 223: The determination of taste and odour in drinking waters 2010 - Methods for the Examination of Waters and Associated Materials, Bristol: Environment Agency.

World Health Organization (WHO) (2004) Guidelines for Drinking-Water Quality, Vol. I: Recommendations, 3rd edn, Geneva: WHO. 